\title{
Perimenopausal women's views on taking hormone replacement therapy to prevent osteoporosis
}

\author{
Juliet Draper, Martin Roland
}

\begin{abstract}
Objective-To find out perimenopausal women's views on taking hormone replacement therapy to prevent osteoporosis.

Design-Semistructured postal questionnaire survey; the questionnaire was enclosed with a letter to explain the purpose of the study and to give patients some information about hormone replacement therapy and osteoporosis.

Setting-Mixed social class, urban general practice with 12000 registered patients.

Patients-All women aged 50, 51, or 52 were selected from the age-sex register; 102 women were identified and $84(87 \%)$ replied to the questionnaire.

Main outcome measures-Response rates to questions on interest in taking hormone replacement therapy, the importance of preventing osteoporosis, and worries about side effects of the treatment.

Results-More than three quarters of the respondents $(65)$ were interested in taking hormone replacement therapy to prevent osteoporosis, but 48 of them would have liked further information. Sixty four women thought that it was very important to prevent osteoporosis. More than half of the respondents (51) were worried about side effects of the treatment, but only 15 women thought that continued menstruation would be a major disadvantage.

Conclusions-There is considerable interest among perimenopausal women in taking hormone replacement therapy to prevent osteoporosis. The resource implications for primary care in meeting this interest are substantial.
\end{abstract}

\section{Introduction}

Hormone replacement therapy has been available for the alleviation of menopausal symptoms for over 30 years. Interest has recently focused on the place of hormone replacement therapy in preventing osteoporosis, and there is now a considerable amount of evidence to show that oestrogens taken within two years of the menopause and for at least five years help to prevent this condition. ' 2 Osteoporosis is an important health problem in older women. Nearly $50 \%$ of women will have sustained a fracture of the hip, of a vertebra, or of the wrist by the time they reach the age of 70 . Fractures of the hip are associated with an excess mortality of up to $20 \%$ within the first year, ${ }^{3+}$ and osteoporosis of the spine is an important cause of back pain in postmenopausal women.

We were interested in the possibility of extending preventive care services to perimenopausal women in our practice. Our study was designed to see whether women would be interested in information about hormone replacement therapy and its use in preventing osteoporosis and whether they would take hormone replacement therapy if offered this form of treatment.

\section{Methods}

The study was carried out in a mixed social class, urban general practice in Cambridge which had 12000 registered patients in 1988. The sample of patients for our study was selected from the age-sex register of the practice and included all women who were born in 1936 or 1937 and were therefore aged 50,51, or 52 at the time of the survey.

A letter was sent to each patient from the doctor with whom they were registered, explaining the purpose of the study and giving some information about the value of hormone replacement therapy in treating common menopausal symptoms and preventing osteoporosis (figure). Patients were also sent a questionnaire and asked to return it, completed, in a stamped addressed envelope. A reminder and second copy were sent to patients who did not return the original questionnaire, and those who again did not respond were telephoned when possible.

The questionnaire was semistructured and respondents were encouraged to write details about points if they wished. Questions were included on socioeconomic state, age, marital state, number of children, own employment, partner's employment, and educational attainment. The social class of each patient was determined in two ways with the classification of the Office of Population Censuses and Surveys. Firstly, "social class" was determined on the basis of the respondent's occupation for single women and on the basis of the husband's occupation for married women. Secondly, "own social class" was determined using the respondent's occupation for the whole of the sample. All analyses relating to social class were carried out with the two methods of determining the patient's social class.

Women were asked whether they were worried about menopausal problems and whether they were experiencing such problems. They were asked for details about their periods to establish their menopausal state; whether they had ever taken oral contraceptives and if they had found this to be a satisfactory form of contraception; and whether they had ever consulted a doctor about menopausal problems. They were also asked whether they had heard about hormone treatment for menopausal symptoms, whether they were currently taking hormone replacement therapy, whether they would be interested in receiving more information about the subject, and if they would be interested in taking hormone replacement therapy to prevent osteoporosis. Finally, they were asked to describe any worries that they had about side effects of the treatment and to grade the importance of preventing five named menopausal problems including osteoporosis.

\section{Results}

In all 102 women were identified from the age-sex register as having been born in 1936 or 1937, but three

Dr Draper. 
The Surgery

125 Newmarket Road

June 1988

Cambridge

We would like to know more about the views of women who have reached the change of life (the menopause).

Many women have problems while they are going through the menopause. These include:
hot flushes
irritability
depression
vaginal dryness

and a bone condition called OSTEOPOROSIS

OSTEOPOROSIS is caused by thinning of the bones. Bones that become thinned by OSTEOPOROSIS are more likely to break - the HIP and the WRIST are common places for breaks. OSTEOPOROSIS may also cause back pain. These problems become more common as women get older.

Some women take hormone treatment while they are going through the menopause (hormone replacement therapy) to help to reduce troublesome symptoms.

Taking hormone treatment for five years can help to prevent OSTEOPOROSIS as well as some of the other problems of the change of life. Some women are more likely to get osteoporosis than others, but at the moment it is difficult to tell which women will develop this problem.

A disadvantage of taking hormone replacement therapy is that most women go on having periods while they are on treatment.

It would help us to plan preventive health services for menopausal women if we knew whether women who might be helped by hormone replacement therapy would be interested in taking it.

Please would you answer the questions below by filling in the boxes which apply to you, and please add any comments which you would like to make at the end.

Letter sent to all patients to explain purpose of study and to give some information about osteoporosis and value of hormone replacement therapy

of them were excluded from the study by their doctors and two had moved off the list. The questionnaire was sent to the remaining 97 women and 84 replies were received, giving a response rate of $87 \%$, though not all the women answered every question (in most cases response rates are given in absolute figures). Eighty one of the women were aged 50,51 , or 52 (two were 53 and one was 54$) ; 64(77 \%)$ were living with a spouse or partner; and $76(91 \%)$ had children. Table I shows the distribution of social class in the respondents compared with the 1981 census figures from the Office of Population Censuses and Surveys. ${ }^{6}$

Fifty women either had not had a period for over a year or reported irregular periods, and 18 had had a hysterectomy. Forty two women had already experienced menopausal symptoms, 24 had not, and 14 were unsure. Forty five women described their problems, the commonest being hot flushes (28), depression (10), tiredness (nine), headaches (eight), and decreased libido (seven). Four women were already taking hormone replacement therapy. In response to the question "Are you worried about problems you might get with the menopause?" 12 women were "fairly worried" and three were "very worried," but 66 were either "not at all worried" or "not too worried." The commonest worries described were osteoporosis, depression, mood changes, hot flushes, and obesity. These responses were independent of social class.

Thirty eight women knew somebody who had experienced menopausal symptoms, and 63 had heard about the value of hormone replacement therapy in helping these symptoms. Most of the 20 women who had not heard about hormone replacement therapy were in social classes III manual, IV, or V. More than half of the sample (46 women) were interested in receiving more information about hormone replacement therapy, but 15 expressed no such interest and 21 were unsure.
Thirty three women had previously consulted a doctor about menopausal problems. Of the 48 who had not, 33 made a comment, the commonest being that their symptoms were not severe enough to consult their general practitioner (14) or that the menopause was a natural process (nine). Six patients thought that their doctors were too busy or they did not like to worry them.

Respondents were asked whether they would be interested in taking hormone replacement therapy to prevent osteoporosis if they were recommended to do so. Table II shows that more than three quarters of the women expressed an interest and that over half wanted more information. There were no significant associations between these responses and social class, educational attainment, worries about menopausal problems, or whether the women had consulted their doctors about menopausal problems. There were also no significant associations between interest in taking hormone replacement therapy and whether the respondents knew other women who were either suffering from menopausal symptoms or taking hormone replacement therapy. Women were, however, significantly less likely to be "definitely interested" in taking hormone replacement therapy to prevent osteoporosis if they were worried about side effects $\left(\chi^{2}=26 \cdot 2, p<0.001\right)$. They were also less likely to be interested, although not significantly so, if they were worried about continuing to menstruate while taking hormone replacement therapy.

More than half of the women (51) said that they would worry about the side effects of hormone replacement therapy if recommended to take it; 10 said that they would not worry and 20 were unsure. When invited to detail their worries about the side effects of hormone replacement therapy 15 women responded and mentioned lack of information about the hormones and their side effects, worries about cancer, and

TABLE I - Distributions of social class nationally from 1981 census and in 84 respondents according to husband's occupation if married or respondent's occupation if single (social class) and according to respondent's occupation alone (own social class). Values are percentages (numbers)

\begin{tabular}{|c|c|c|c|}
\hline & \multicolumn{2}{|c|}{ Respondents' } & \multirow[b]{2}{*}{1981 Census } \\
\hline & Social class & Own social class & \\
\hline \multicolumn{4}{|l|}{ Social class: } \\
\hline I & $4(3)$ & $-(0)$ & 5 \\
\hline II & $10(8)$ & $12(10)$ & 20 \\
\hline III Non-manual & $25(21)$ & $39(33)$ & 11 \\
\hline III Manual & $35(29)$ & $11(9)$ & 31 \\
\hline IV & $11(9)$ & $12(10)$ & 14 \\
\hline $\mathrm{V}$ & $5(4)$ & $21(18)$ & 4 \\
\hline Unclassified & $12(10)$ & $5(4)$ & 15 \\
\hline
\end{tabular}

TABLE $\mathrm{II}$-Interest of 84 respondents in taking hormone replacemen therapy to prevent osteoporosis

\begin{tabular}{lr}
\hline & No \\
\hline Definitely interested & 17 \\
Interested but would like more information & 48 \\
Would like more information but would probably not be interested & 9 \\
Not interested & 8 \\
No response & 2
\end{tabular}

TABLE III-Perceived importance of preventing five menopausal symptoms by 84 respondents grading them from 1 (not important to prevent) to $\overline{5}$ (very important to prevent)

\begin{tabular}{lrrrrrr}
\hline & \multicolumn{5}{c}{ Grade } & \\
\cline { 2 - 6 } & 1 & 2 & 3 & 4 & 5 & No response \\
\hline Hot flushes & 9 & 9 & 15 & 9 & 26 & 16 \\
Vaginal dryness & 2 & 6 & 18 & 9 & 21 & 28 \\
Osteoporosis & 2 & 1 & 4 & 4 & 64 & 9 \\
Depression & 3 & 3 & 6 & 11 & 46 & 15 \\
Skin aging & 8 & 4 & 19 & 8 & 24 & 21 \\
& & & & & &
\end{tabular}


whether the benefits of such treatment outweighed the risks.

The contraceptive pill had been taken by 35 women, of whom 22 had found it satisfactory. No associations were apparent between women's experience of the contraceptive pill and their attitude to hormone replacement therapy or its side effects. Women who had taken the contraceptive pill, however, were more likely to have heard of hormone replacement therapy but the difference was not significant (30 out of 35 women $(86 \%)$ who had taken oral contraceptives compared with 32 out of $47(68 \%)$ who had not).

The respondents were given a list of five menopausal symptoms and asked to grade the importance of preventing each symptom by circling a number from 1 (not important to prevent) to 5 (very important to prevent). The results are shown in table III. Women clearly thought that the most important symptoms to prevent were osteoporosis and depression. Women in social classes III manual, IV, and V were most interested in preventing depression and skin aging, but there were no relations between responses to the three other symptoms and social class. It is notable that 64 women thought that it was very important to prevent osteoporosis. Of these women 48 (75\%) thought that it was equally important to prevent depression, $46(72 \%)$ to prevent vaginal dryness, 34 $(53 \%)$ to prevent skin aging, and $31(48 \%)$ to prevent flushing.

Finally, when asked whether they would mind continuing to menstruate while taking hormone replacement therapy 15 women said that they would not mind, 27 that it would be a minor disadvantage, and 15 that continuing to have periods would be such a major disadvantage that they would not be prepared to try the treatment. There was no relation between these responses and a history of menstrual problems.

\section{Discussion}

Most women currently taking hormone replacement therapy are doing so to alleviate menopausal symptoms. ${ }^{7}$ The use of hormone replacement therapy in the primary prevention of osteoporosis is, however, increasing and a recent survey found that over $40 \%$ of general practitioners regarded such treatment as "first line" in preventing osteoporosis. ${ }^{8}$

Although doctors are becoming more aware of the benefits of hormone replacement therapy, there is some professional disquiet about the introduction of widespread prophylactic treatment. A study of women already taking hormone replacement therapy found that in $21 \%$ of the patients surveyed the treatment had been initiated in response to a request from the patient. Bearing in mind changing professional attitudes, our survey was carried out to see whether perimenopausal women would be interested in taking hormone replacement therapy to prevent osteoporosis.

We found that over three quarters of the women surveyed expressed an interest in taking hormone replacement therapy to prevent osteoporosis and this interest was expressed by women of varied social class and educational achievement in a practice of mixed social classes. Two thirds of the sample, however, said that they would like more information. When presented with a number of menopausal problems they judged osteoporosis to be the most important to prevent. Contrary to the views of some doctors,${ }^{8}$ less than a fifth of our respondents regarded continued menstruation as a major drawback of hormone replacement therapy.

There was little association between the responses to this questionnaire and social class, although women from the lower social classes were less likely to have heard of hormone replacement therapy. They were also more likely to rank depression as an important menopausal symptom to prevent, perhaps because depression is more prevalent in patients from the lower social classes. ${ }^{9}$ It should be noted, however, that the number of patients in our study was small and therefore the power of the study to detect associations between variables was relatively low.

Our study was undertaken partly to estimate the likely interest of perimenopausal women in preventive care for osteoporosis. The results showed that when women are given a modest amount of information on the prevention of osteoporosis by taking hormone replacement therapy they show considerable interest in obtaining further information and treatment. The period of treatment required to prevent fractures occurring is unknown. Lindsay suggested that it is probably at least five years if treatment is started immediately after the menopause but that it may be at least 10 years if treatment is delayed for several years. This view was supported by a consensus conference on osteoporosis in $1987 . .^{10}$

Some of the positive responses might have resulted from the introductory letter that was sent to respondents (figure). We thought that it would be difficult to ask questions about osteoporosis without giving some explanation of the term, but details about the possible benefits of treatment were kept as low key as possible. Had we suggested that 10 years rather than five years was the necessary period of treatment then the number of patients expressing interest in preventive treatment might have been reduced. In addition, some patients might have understood from the letter that the development of osteoporosis occurs at the time of the menopause, which might also have encouraged a more receptive attitude to hormone replacement therapy than if they had understood that symptoms usually occur from the age of 70 .

From the experience of one practice based clinic for menopausal women it is clear that considerable resources are needed to undertake recall, education, treatment, and follow up of perimenopausal women (J Coope, personal communication). The resource implications would be substantial if general practice responded to the demand for such services in the future.

We are grateful to the women in our survey who answered the questionnaire and to our supportive partners. We thank Mildred Blaxter, Kate Hunt, Hilary Thomas, Beth Alder, Adrian Crisp, and members of the Fenland Research Club for their comments on the design of the study and drafts of this paper.

Lindsay R. Prevention of osteoporosis. Clin Orthop 1987;222:44-59.

2 Barzal US. Fstrogens in the prevention and treatment of postmenopausal osteoporosis: a review Am $\mathcal{7}$ Med 1988:55:847-9.

3 Jensen FG, Christiansen C, Boesen J, Hegedus V, Transbol I. Epidemiology of postmenopausal spinal and long bone fractures. Clin Orthop 1982;166: $75-81$

4 Cummings SR, Kelsey JL, Nevitt MC, O'Dowd KJ. Epidemiology of osteoporosis and osteoporotic fractures. Epidemiol Rev 1985;7:178-208. 5 Office of Population Censuses and Surveys. Classification of occupations. London: HMSO, 1980.

6 Office of Population Censuses and Surveys. National report 1981. Part 2. London: HMSO, 1983.

7 Hunt K. Perceived value of treatment among a group of long term users of hormone replacement therapy. I $R$ Coll Gen Pract 1988;38:398-401.

Shears M-R. Brighton practitioners' attitudes to hormone replacement therapy. Practitioner 1989;233:146-9.

Brown GW, Harris T. Social origins of depression: a study of psychiatric disorders in women. London: Tavistock, 1978.

10 Anonymous. Consensus development conference: prophylaxis and treatment of osteoporosis. Br Med f 1987;295:914-5.

Accepted 19 fanuary 1990 